\title{
KARAKTERISASI SINTER SILIKA MATA AIR PANAS GARARA KAB. SOLOK DAN MATA AIR PANAS SAPAN MALULUANG KAB. SOLOK SELATAN MENGGUNAKAN METODE ANALISIS TERMAL
}

\author{
Ardian Putra*, Rizky Ramadhan, Rahmat Ilham \\ Laboratorium Fisika Bumi, Jurusan Fisika \\ Fakultas Matematika dan Ilmu Pengetahuan Alam, Universitas Andalas \\ Kampus UNAND Limau Manis, Padang, 25163, Indonesia \\ *Korespondensi ke: ardianputra@sci.unand.ac.id
}

( Diterima:21 November 2018; Direvisi: 23 Februari 2019; Diterbitkan: 01 Maret 2019)

\begin{abstract}
ABSTRAK
Telah dilakukan karakterisasi sinter silika dari mata air panas Garara, Kabupaten Solok, dan mata air panas Sapan Maluluang, Kabupaten Solok Selatan, Sumatera Barat. Sinter silika dimurnikan untuk meningkatkan kadar $\mathrm{SiO}_{2}$ menggunakan metode ekstraksi padat-cair. Peningkatan kadar $\mathrm{SiO}_{2}$ dapat dilihat berdasarkan hasil uji XRF (X-Ray Fluorescence). Kadar $\mathrm{SiO}_{2}$ Sampel sinter silika Garara meningkat, dari 54,28 \% menjadi 79,034 \% setelah pemurnian. Pada sampel sinter silka Sapan Maluluang kadar $\mathrm{SiO}_{2}$ meningkat dari 83,39\%, menjadi 95,216 \%. Metode Analisis Termal atau Differential Thermal Analysis (DTA) digunakan untuk melihat perubahan fasa kristalin dari sintel silika. Berdasarkan pengujian DTA diperoleh hasil transisi gelas sampel sinter silika Garara dan Sapan Maluluang berturut-turut pada suhu 530,83 ${ }^{\circ} \mathrm{C}$ dan $551,52{ }^{\circ} \mathrm{C}$. Silika Garara mengalami perubahan $\alpha \rightarrow \beta$-quartz pada suhu $643,66{ }^{\circ} \mathrm{C}$ dan perubahan $\beta$-quartz $\rightarrow \beta$ trydimite terjadi pada suhu $811,48{ }^{\circ} \mathrm{C}$. Untuk hasil DTA sinter silika Sapan Maluluang terjadi perubahan $\alpha \rightarrow \beta$-quartz pada suhu $657,48{ }^{\circ} \mathrm{C}$ dan transisi $\beta$-quartz $\rightarrow \beta$-trydimite terjadi pada suhu $700,45^{\circ} \mathrm{C}$. Hal ini memperlihatkan sinter silika dengan kandungan silika yang lebih tinggi dan berstruktur amorf memiliki transisi gelas dan suhu transisi $\alpha \rightarrow \beta$-quartz yang le bih tinggi dan transisi $\beta$-quartz $\rightarrow \beta$-trydimite yang lebih rendah dibandingkan sinter silika yang masih mengandung karbonat.

Kata Kunci : sinter silika, ekstraksi, pemurnian, analisis termal, mata air panas Garara, mata air panas Sapan Maluluang
\end{abstract}




\begin{abstract}
Thermal analysis of siliceous sinter from Garara hot springs, Solok, and Sapan Maluluang hot springs, South Solok, West Sumatra had been characterized. The siliceous sinter are initially purified to increase the SiO2 content using a solid-liquid extraction method. The purification methode was treaated using leaching method. Increased levels of $\mathrm{SiO}_{2}$ can be seen from XRF (XRay Fluorescence) test results. $\mathrm{SiO}_{2}$ content Garara siliceous sinter samples increased from $\mathrm{SiO}_{2}$ $54.28 \%$ to $79.034 \%$ after purification. In the Sapan Maluluang siliceous sinter sample, the initial $\mathrm{SiO} 2$ increased from $83.39 \%$, to $95.216 \%$ after refining. Thermal analysis was carried out using Differential Thermal Analysis (DTA) method to see the crystalline phase changes from silica sinter. Based on DTA test, the glass transition from sample at Garara and Sapan Maluluang hot springoccured at $530.83{ }^{\circ} \mathrm{C}$ dan $551.52{ }^{\circ} \mathrm{C}$, respectively.temperature The change $\alpha \rightarrow \beta$-quartz of Garara sample occurs at $543.66^{\circ} \mathrm{C}$, and $\beta$-quartz $\rightarrow \beta$-tridymite occurs at $811.48^{\circ} \mathrm{C}$. Another sample from Sapan Maluluang, $\alpha \rightarrow \beta$ quartz changes at $657.48^{\circ} \mathrm{C}$ and $\beta$-quarz $\rightarrow \beta$-tridymite changes at $700.45^{\circ} \mathrm{C}$. It shows that high content of silica and amorf structure has higher glass transition and $\alpha \rightarrow \beta$-quartz transition, lower $\beta$-quart $z \rightarrow \beta$-trydimite transition than siliceous sinter that still contains carbonate.

Keywords: silica sinter, extraction, purification, thermal analysis, Garara hot spring, Sapan Maluluang hot spring
\end{abstract}

\title{
1. PENDAHULUAN
}

Pada sistem panas bumi silikon dan oksigen merupakan unsur yang sering hadir ke permukaan dalam bentuk sinter silika $\left(\mathrm{SiO}_{2}\right)$. Sinter silika berasal dari reservoir panas bumi bersuhu tinggi yang muncul ke permukaan sebagai manifestasi panas bumi. Silika biasanya dimanfaatkan untuk berbagai keperluan dengan ukuran tergantung aplikasinya seperti, pada industri ban, karet, gelas, semen, beton, tekstil, kertas, kosmetik, elektronik, pasta gigi, dan lain-lain.

Indonesia saat ini memiliki total 252 lokasi Wilayah Kerja Pertambangan (WKP) panas bumi yang tersebar di seluruh Indonesia mengikuti jalur pembentukan gunung api yang membentang dari Sumatera, Jawa, Nusa Tenggara, Sulawesi sampai Maluku. Penyebaran potensi panas bumi juga ditemukan di Sumatera Barat, diantaranya di Kabupaten Solok dan Kabupaten Solok Selatan. Tingginya potensi panas bumi yang ada di Sumatera Barat ini berpeluang meningkatnya produksi sinter silika, sehingga diperlukan antisipasi dan penggunaanya. Tahapan awal yang perlu dilakukan yaitu dengan mengetahui karakteristik dari sinter silika ini, salah satunya yaitu karakteristik termal sinter silika.

Penelitian terkait karakterisasi sinter silika sebelumnya pernah dilakukan oleh Herdianita, dkk. (2000), Valles, dkk. (2008), dan Putra, dkk. (2017). Herdianita dkk. (2000), meneliti mikrostruktur dari sinter silika, yaitu mengenai perubahan mineral dan tekstur sinter silika di Islandia Utara dan New Zealand yang dikarakterisasi menggunakan teknik analisa termal, yaitu Differential Thermal Analysis (DTA) dimana pada sampel silika Wairakei hasilnya menunjukan peristiwa endoterm terjadi pada suhu $<200^{\circ} \mathrm{C}$ dan eksoterm terjadi pada $1200^{\circ} \mathrm{C}$ sampai $1300^{\circ} \mathrm{C}$. Peristiwa eksoterm menunjukan terjadinya kristalisasi kristobalit. Transformasi $\beta \rightarrow \alpha$-kristobalit terjadi pada pendinginan $188^{\circ}$ C. Valles, dkk. (2008), juga meneliti mikrostruktur sinter silika yang terdapat di lapangan panas bumi EL Tatio Chili. Karakterisasi sampel juga menggunakan teknik yang sama. Berdasarkan hasil pengujian DTA, saat pemanasan menunjukan proses kristobalit pada suhu $1000{ }^{\circ} \mathrm{C}$, dan saat pendinginan menunjukan perubahan $\beta \rightarrow \alpha$ kristobalit pada suhu $200^{\circ}$ C.Putra, dkk (2018) melakukan karakterisasi sinter silika pada mata air panas Garara dan Bawah Kubang Kabupaten Solok, untuk Kabupaten Solok Selatan dilakukan di mata air Panas Sapan Maluluang. Pada penelitiannya karakterisasi 
dilakukan menggunakan teknik X-Ray Diffraction (XRD), Scanning Electron Microscopy (SEM) dan Fourier Transform Infra-red (FTIR). Berdasarkan penelitian hasilnya menunjukan endapan sinter silika mata air panas Sapan Maluluang memiliki fasa opal-A (non-kristalin) dengan usia <10.000 tahun, sedangkan mata air panas Garara memiliki fasa opal-CT dengan usia yang lebih tua dibandingkan dengan sinter silika dari mata air panas Sapan Maluluang.

Berdasarkan potensi kehadiran mineral silika yang ada di daerah Kabupaten Solok dan Solok Selatan ini, maka penelitian mengenai karakterisasi sinter silika yang ada di lokasi ini perlu dilakukan sebagai pemanfaatan sumber daya mineral lokal yang ada. Adapun penelitian ini ialah lanjutan dari peneliti sebelumnya yaitu penelitian Putra dkk. (2017), namun pada penelitian ini sinter silika akan dimurnikan terlebih dahulu dengan metode ektraksi padat - cair. Selanjutnya kemurnian silika akan di analisis berdasarkan data XRF (X-Ray Fluoresence). Teknik karakterisasi yang digunakan ialah karakterisasi dengan menggunakan metode analisis termal yaitu Differential Thermal Analysis (DTA).

\section{METODE PENELITIAN}

\subsection{Alat dan Bahan}

Alat dan bahan yang digunakan pada proses ektraksi sampel uji sinter silika berupa dua buah sampel uji sinter silika dari masing-masing lokasi, $\mathrm{NaOH} 3 \mathrm{M}$, Akuades, dan $\mathrm{HCl} 1$ $\mathrm{M}$, ayakan $100 \mathrm{mesh}$, lumpang, alu, gelas beaker $250 \mathrm{ml}$, Kertas, $\mathrm{pH}$ meter, stirer, oven, furnace. Alat dan bahan yang digunakan untuk mengkarakterisasi sampel yaitu TGA 92, XRF Panalytical Epsilon.

\subsection{Pemurnian Sinter Silika}

Silika dimurnikan dengan metode ektraksi padat cair. $25 \mathrm{~g}$ sampel direndam dalam larutan $\mathrm{HCl} 10 \mathrm{M}$ selama 12 jam untuk melarutkan pengotor yang ada pada sampel. Hasil rendaman dipisahkan dan dicuci menggunakan aquades sebanyak 5 kali, dan disaring menggunakan kertas saring. Sinter silika hasil saring selanjutnya direaksikan dengan 100 $\mathrm{ml} \mathrm{NaOH} 3 \mathrm{M}$, kemudian larutan dipisahkan dan dicuci kembali menggunakan aquades sebanyak 5 kali supaya sinter silika bersifat netral. Sinter silika yang telah bersifat netral selanjutnya disaring menggunakan kertas saring, dan proses pengeringan dilakukan di dalam oven pada suhu $110^{\circ} \mathrm{C}$ selama 6 jam untuk menghilangkan kadar air.

\subsection{Pengujian}

Karakterisasi kadar mineral dilakukan menggunakan XRF. Karakterisasi ini berguna melihat persentase kandungan kadar silika pada sampel sinter silika hasil ekstraksi. Data keluaran dari uji XRF merupakan persentase kandungan kadar mineral yang diuji.

Pengujian DTA dilakukan untuk menganalis perubahan fasa kristalin sampel sinter silika. Massa sampel yang digunakan yaitu sebanyak $50 \mathrm{mg}$ dan pemanasan dilakukan pada suhu $30-1000{ }^{\circ} \mathrm{C}$ dengan laju pemanasan $10{ }^{\circ} \mathrm{C} /$ menit. Sampel inert yang digunakan sebagai pembanding adalah alumina $\left(\mathrm{Al}_{2} \mathrm{O}_{3}\right)$ karena alumina memiliki titik lebur yang sangat tinggi yaitu $2050{ }^{\circ} \mathrm{C}$. Data yang terbaca pada uji DTA ini merupakan data eksoterm dan endoterm di setiap suhu. 


\section{HASIL DAN DISKUSI}

\subsection{Hasil Pemurnian Sinter Silika}

Hasil ekstraksi dapat dilihat pada Gambar 1, dimana sampel sinter silika (a) yaitu sampel sinter silika yang berasal dari mata air panas Sapan Maluluang memiliki warna yang putih sedangkan untuk sampel (b) yang berasal dari mata air panas Garara memiliki warna coklat. Hal ini dikarenakan perbedaan kemurnian dan komposisi asal dari sinter silika tersebut.

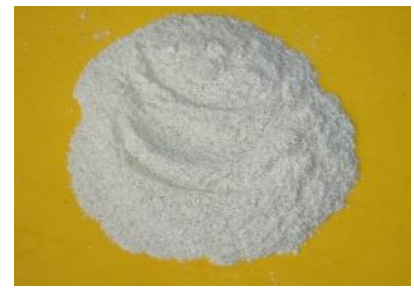

(a)

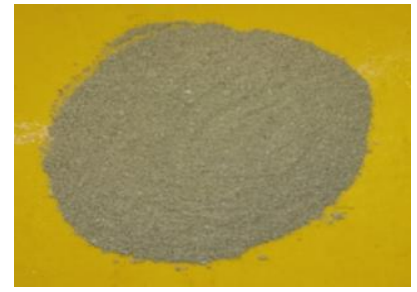

(b)

Gambar 1 Hasil ekstraksi sinter silika (a) sampel mata air panas Sapan Maluluang, dan (b) sampel mata air panas Garara

\subsection{Hasil Pengujian Kandungan Mineral Sinter Silika}

Tabel 1 merupakan hasil perbandingan kandungan mineral sinter silika mata air panas Garara sebelum dan setelah dilakukan pemurnian. Berdasarkan data analisis penelitian Dona dan Putra (2016) kadar mineral silika di mata air panas Garara, Nagari Cupak, Kabupaten Solok adalah sebesar 54,28 \%. Pada sampel silika mata air panas Garara kadar silika meningkat 25,024 \% dari sebelumnya, dimana awalnya kadar silika sebesar 54,280 $\%$ dan setelah dilakukan proses ekstraksi kadar meningkat menjadi 79,034 \%. Kandungan mineral yang paling banyak hilang setelah proses permurnian yaitu $\mathrm{Fe}_{2} \mathrm{O}_{3}$ dan $\mathrm{Al}_{2} \mathrm{O}_{3}$ dimana secara berturut-turut awalnya sinter silika memiliki kandungan sebesar 17,48\% dan $18,48 \%$, kemudian setelah pemurnian kandungan tersebut mengalami pengurangan kadar menjadi 3,094 \% dan 2,084 \%. Dari beberapa mineral yang mengalami pengurangan konsentasi, terdapat juga beberapa unsur yang tidak bisa dihilangkan atau dimurnikan yaitu seperti $\mathrm{CaO}$.

Tabel 1 Hasil pengujian kandungan mineral sinter silika mata air panas Garara

\begin{tabular}{ccc}
\hline Mineral Oksida & $\begin{array}{c}\text { Kandungan sebelum pemurnian } \\
\text { (Dona dan Putra, 2016) }(\%)\end{array}$ & $\begin{array}{c}\text { Kandungan setelah } \\
\text { pemurnian }(\%)\end{array}$ \\
\hline $\mathrm{SiO}_{2}$ & 54,28 & 79,304 \\
$\mathrm{CaO}$ & 3,33 & 8,686 \\
$\mathrm{MgO}$ & - & 4,642 \\
$\mathrm{Fe}_{2} \mathrm{O}_{3}$ & 17,48 & 3,094 \\
$\mathrm{Al}_{2} \mathrm{O}_{3}$ & 18,48 & 2,082 \\
$\mathrm{P}_{2} \mathrm{O}_{5}$ & 3,37 & 0,536 \\
$\mathrm{Ag}_{2} \mathrm{O}$ & - & 0,514 \\
$\mathrm{MnO}$ & - & 0,41 \\
lainnya & - & 0,458 \\
\hline
\end{tabular}


Kemurnian silika yang didapatkan pada proses ekstraksi ini meningkat dikarenakan penggunaan $\mathrm{HCl}$ dengan konsentrasi tinggi dapat menghilangkan zat-zat pengotor seperti zat organik yang melekat pada sampel. Pelarut $\mathrm{NaOH}$ juga dapat melarutkan zat pengotor lainnya.

Pada sinter silika Sapan Maluluang peningkatan konsentrasi silika terjadi sebesar 7,766 \% dari sebelumnya (Tabel 2). Pada dasarnya kadar silika pada lokasi ini sudah cukup tinggi yaitu $87,42 \%$ dan meningkat menjadi $95,216 \%$ setelah ekstraksi. Mineral yang paling banyak mengalami pengurangan kadar yaitu $\mathrm{Al}_{2} \mathrm{O}_{3}$ dan $\mathrm{P}_{2} \mathrm{O}_{5}$. Berdasarkan data penelitian Endhovani dan Putra (2016), awalnya mineral ini secara berturut-turut memiliki persentase sebesar $6,10 \%$ dan 3,68 \%, kemudian setelah ekstraksi menjadi 3,176\% dan $0,368 \%$. Pada proses pemurnian sampel sinter silika Sapan Maluluang terdapat juga beberapa unsur yang tidak dapat dihilangkan untuk yaitu seperti $\mathrm{CaO}$ dan $\mathrm{TiO}_{2}$, yang mana pada proses pemurnian ini tidak terjadi pengurangan konsentrasi.

Tabel 2 Hasil pengujian kandungan mineral sinter silika mata air panas Sapan Maluluang

\begin{tabular}{ccc}
\hline Mineral Oksida & $\begin{array}{c}\text { Kandungan sebelum pemurnian } \\
\text { (Endhovani dan Putra, 2016) (\%) }\end{array}$ & $\begin{array}{c}\text { Kandungan setelah } \\
\text { pemurnian }(\%)\end{array}$ \\
\hline $\mathrm{SiO}_{2}$ & 87,42 & 95,216 \\
$\mathrm{Al}_{2} \mathrm{O}_{3}$ & 6,10 & 3,176 \\
$\mathrm{CaO}$ & 0,74 & 0,434 \\
$\mathrm{P}_{2} \mathrm{O}_{5}$ & 3,68 & 0,327 \\
$\mathrm{MgO}$ & 0,47 & 0,207 \\
$\mathrm{~K} \mathrm{O}$ & 0,35 & 0,079 \\
$\mathrm{Cl}$ & 1,11 & 0,067 \\
$\mathrm{Ag}_{2} \mathrm{O}$ & 0.29 & 0,059 \\
$\mathrm{TiO}_{2}$ & 0,02 & 0,051 \\
$\mathrm{Cs}_{2} \mathrm{O}$ & 0,01 & 0,011 \\
lainnya & 0,21 & 0.21 \\
\hline
\end{tabular}

\subsection{Analisis Hasil DTA Sinter Silika}

Gambar 2 merupakan grafik DTA pemanasan untuk sampel sinter silika mata air panas Garara. Pada suhu tertentu, fasa silika dapat berubah-ubah seiring dengan dilakukannya pemanasan. Pada suhu $145,66{ }^{\circ} \mathrm{C}$ terjadi peristiwa penyerapan panas dan silika mengalami hidrasi air atau penguapan yang ditandai dengan menurunnya kurva yang disebut dengan peristiwa endoterm. Grafik akan terus meningkat seiring dengan bertambahnya kapasitas panas $\left(c_{p}\right)$ pada sampel. Peristiwa hidrasi air atau penguapan terus terjadi hingga silika mengalami transisi gelas $\left(T_{g}\right)$. 


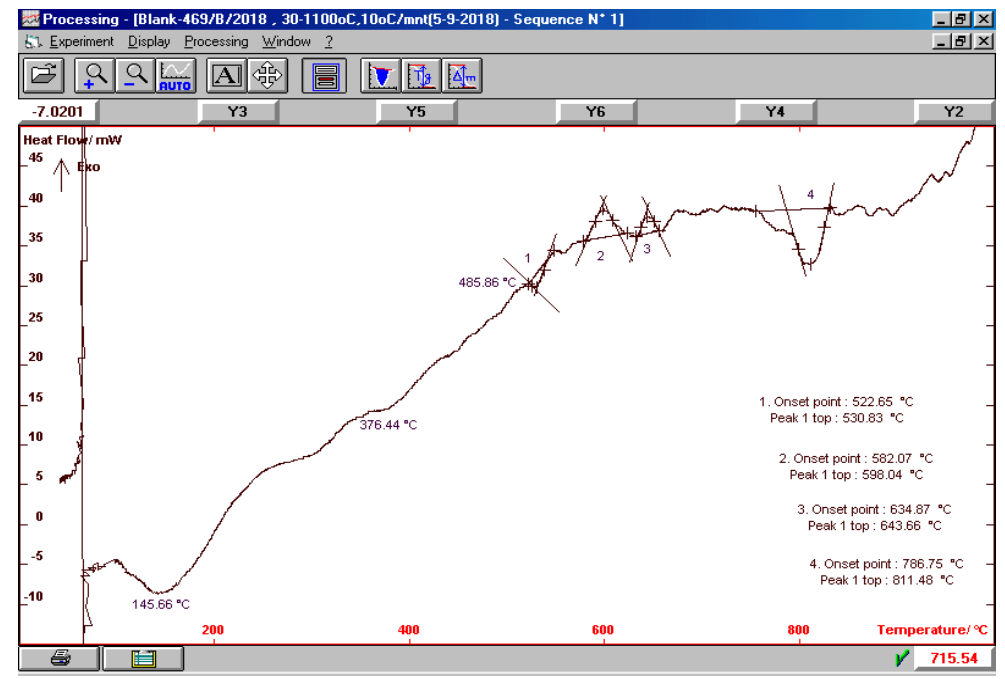

Gambar 2 Hasil DTA pemanasan sinter silika Garara

Pada pengujian ini sampel sinter silika mengalami $T_{g}$ pada daerah yang ditandai dengan daerah (1) pada Gambar 2. $T_{g}$ mulai terjadi pada suhu $522,85^{\circ} \mathrm{C}$ dan puncak transisinya pada suhu $530,83{ }^{\circ} \mathrm{C}$ yang ditandai oleh grafik yang naik secara tiba-tiba. Hal ini dikarenakan terjadi dekomposisi pada silika yang menyebabkan munculnya puncak baru pada grafik. Setelah mengalami transisi gelas, fenomena yang akan terjadi selanjutnya yaitu perubahan fasa silika (Gallagher, 1998). Perubahan fasa $\alpha \rightarrow \beta$-quartz terjadi pada daerah (2) di Gambar 2 yaitu pada suhu $592,07{ }^{\circ} \mathrm{C}$ dan daerah (3) pada suhu $643,66{ }^{\circ} \mathrm{C}$ yang ditandai dengan peristiwa eksoterm. Pada suhu $643,66{ }^{\circ} \mathrm{C}$ fasa silika seutuhnya telah berada dalam fasa $\beta$-quartz yaitu silika yang memiliki struktur kristal hexagonal. Peristiwa perubahan fasa selanjunya terjadi pada daerah (4) di Gambar 2 yaitu transformasi $\beta$-quartz $\rightarrow \beta$-tridymite yaitu pada suhu $811,48{ }^{\circ} \mathrm{C}$.Pada suhu ini terjadi puncak endoterm. Fasa terakhir yang teramati pada penelitian ini yaitu sampai $\beta$-tridymite dengan bentuk kristal hexagonal (Smallman and Bishop, 2000).suhuPada suhu 811,48 ${ }^{\circ} \mathrm{C}$ $-1000{ }^{\circ} \mathrm{C}$ (batas suhu uji alat yang digunakan), tidak terjadi peristiwa perubahan fasa.

Pada fasa $\beta$-tridymite, ini silika masih bersifat metastabil, artinya silika masih bisa dengan mudah untuk berubah fasa (Smallman and Bishop, 2000). Gambar 3 merupakan grafik DTA pendinginan sampel sinter silika garara. Hasil grafik pendinginan merupakan kebalikan dari grafik pemanasan. Pada hasil pendinginan teramati perubahan $\beta$ tridymite $\rightarrow \beta$-quartz terjadi pada suhu $811,48{ }^{\circ} \mathrm{C}$. Peristiwa ini sama halnya pada saat pemanasan, dimana perubahan fasa sebaliknya juga terjadi pada suhu yang sama. Seiring menurunnya suhu sampel fasa silika juga akan kembali ke keadaan dasar hingga silika berada dalam fasa awal yaitu $\alpha$-quartz. 


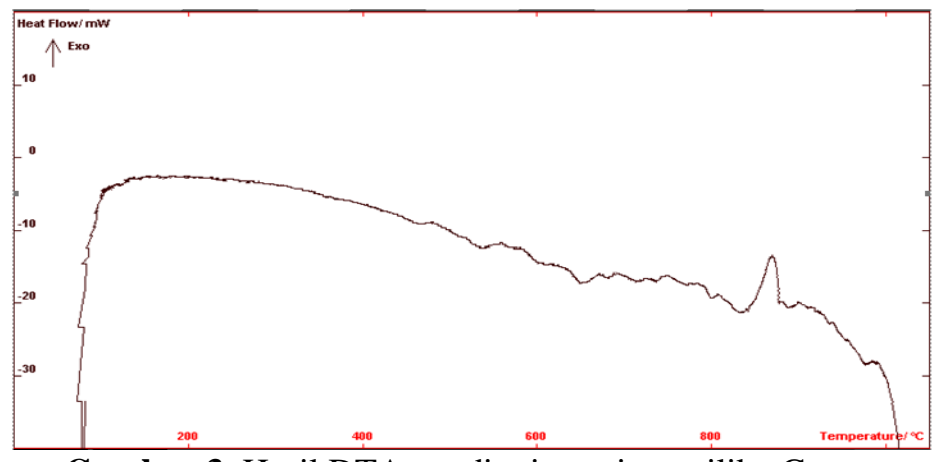

Gambar 3 Hasil DTA pendinginan sinter silika Garara

Pada sampel uji sinter silika mata air panas Sapan Malulang, perubahan fasa kristalin dapat diamati berdasarkan data DTA pemanasan yang dapat dilihat pada Gambar 4. Gambar 4 memperlihatkan beberapa fenomena perubahan fasa silika. Pada suhu $<400$ ${ }^{\circ} \mathrm{C}$, sinter silika mengalami hidrasi air atau penguapan. Hal ini ditandai dengan menurunnya grafik yang mengindikasikan suhusuhu sampel lebih rendah dibandingkan dengan sampel pembanding atau disebut juga dengan peristiwa endoterm. Pada peristiwa ini silika belum mengalami transisi gelas ataupun perubahan fasa.

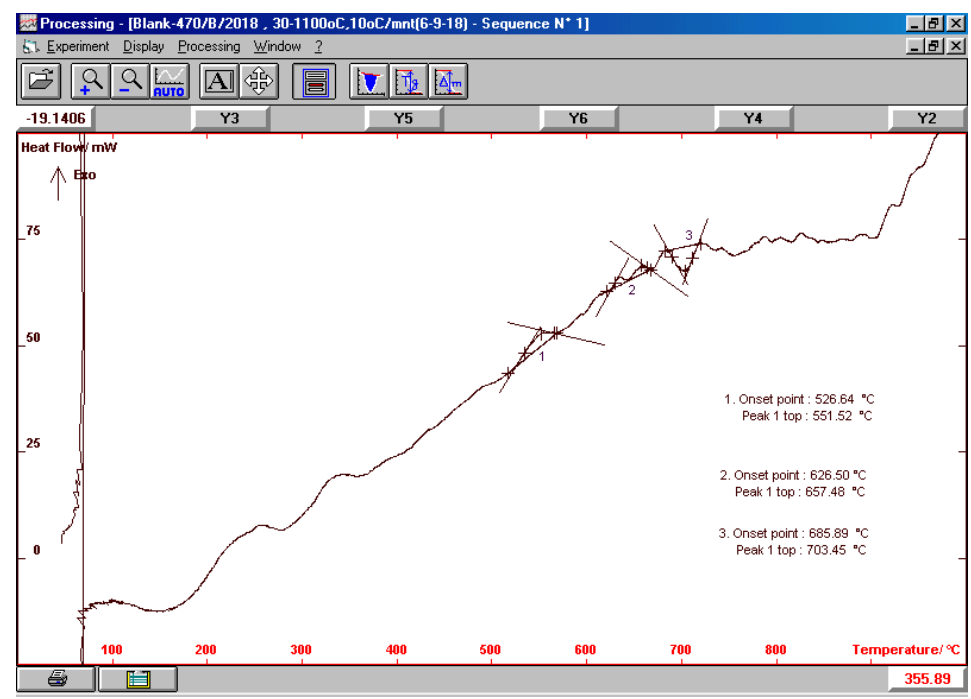

Gambar 4 Hasil DTA pemanasan sinter silika Sapan Maluluang

Transisi gelas $\left(T_{g}\right)$ mulai teramati pada suhu $526,64{ }^{\circ} \mathrm{C}$ dan puncaknya terjadi pada suhu $551,52{ }^{\circ} \mathrm{C}$ yang ditandai pada daerah (1) di Gambar 4. $T_{g}$ ditandai dengan grafik yang tiba-tiba menurun dan kemudian naik kembali. Silika dalam bentuk amorf sebelum mengalami perubahan fasa, silika mengalami transisi gelas terlebih dahulu (Gallagher, 1998). Fenomena eksoterm mulai teramati pada daerah (2) di Gambar 4 pada suhu 626,50 ${ }^{\circ} \mathrm{C}$. Fasa silika mulai mengalami transisi $\alpha \rightarrow \beta$-quartz, namun fasa silika seutuhnya telah berubah menjadi $\beta$-quartz pada suhu $657,48{ }^{\circ} \mathrm{C}$ yang ditandai dengan munculnya dua puncak eksoterm. Pada puncak kedua seutuhnya silika berada dalam fasa $\beta$-quartz dengan struktur kristal hexagonal (Smallman and Bishop, 2000). Pada daerah (3) di Gambar 4,, fenomena endoterm mulai teramati pada suhu $685,89{ }^{\circ} \mathrm{C}$. Hal ini terjadi karena suhu sampel pembanding lebih tinggi dibandingkan suhu sampel sinter silika. Fenomena ini memperlihatkan terjadinya transisi fasa $\beta$-quartz $\rightarrow \beta$-tridymite, namun puncak endoterm 
terjadi pada suhu $700,45^{\circ} \mathrm{C}$. Pada suhu ini, fasa silika secara keseluruhannya telah berada dalam fasa $\beta$-tridymite.

Grafik pendinginan yang diperoleh merupakan kebalikan dari grafik pemanasan. Fasa silika mengalami transisi kristalin ataupun perubahan fasa di suhu yang sama dengan saat pemanasan. Fenomena kebalikan fasa silika dapat kita amati pada Gambar 5, dimana silika mengalami perubahan fasa secara kebalikan yaitu pada suhu $700,45^{\circ} \mathrm{C}$. Pada suhu ini terjadi perubahan $\beta$-tridymite $\rightarrow \beta$-quartz. Pada suhu $626,50{ }^{\circ} \mathrm{C}$, peristiwa kebalikan kembali terjadi yaitu transisi $\beta$-quartz $\rightarrow \alpha$-quartz.

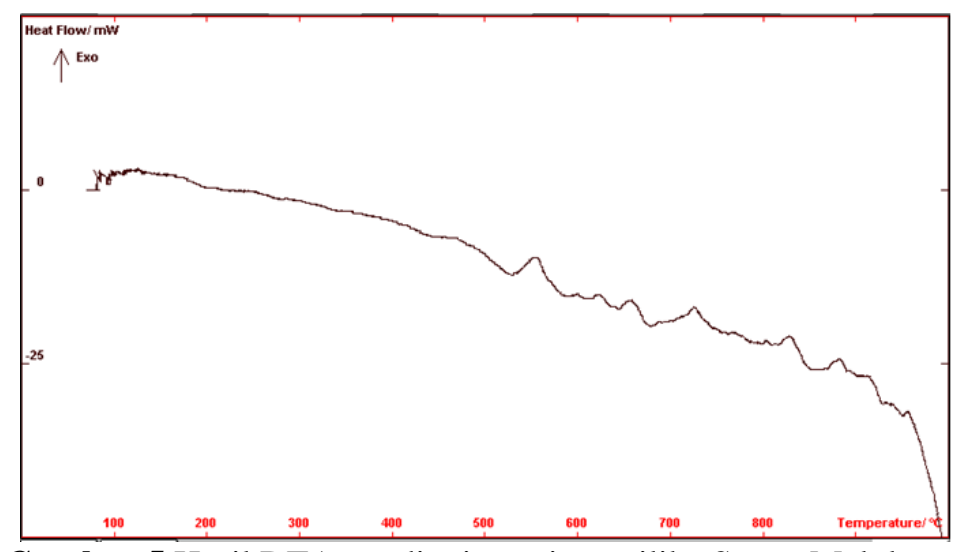

Gambar 5 Hasil DTA pendinginan sinter silika Sapan Maluluang

Berdasarkan analisis data DTA pada masing-masing sampel, terdapat perbedaan suhu transisi gelas dan suhu transisi fasa. Hal ini dikarenakan perbedaan tingkat kemurnian pada sampel uji yang digunakan.Maluluang Silika Sapan Maluluang membutuhkan suhu yang lebih tinggi untuk mengalami transisi gelas, yaitu pada suhu $551,52{ }^{\circ} \mathrm{C}$, sedangkan silika Garara memerlukan suhu transisi gelas yang lebih rendah, yaitu $530,83{ }^{\circ} \mathrm{C}$. Sama halnya dengan transisi gelas, transisi fasa $\alpha \rightarrow \beta$-quartz juga memiliki perbedaan,sampel silika Sapan Maluluang membutuhkan suhu yang lebih tinggi dibandingkan dengan sampel Garara. Berbeda dengantransisi $\beta$-quartz $\rightarrow \beta$-tridymite, sampel Garara membutuhkan suhu yang lebih tinggi.

\section{KESIMPULAN}

Berdasarkan hasil pemurnian dan analisis termal sinter silika pada mata air panas Garara dan mata air panas Sapan Maluluang dapat diambil kesimpulan bahwa pemurnian dengan proses ekstraksi yang dilakukan cukup berhasil ditandai dengan terjadinya peningkatan kadar silika pada sampel uji. Pada karakterisasi analisis termal, suhusampel yang memiliki kandungan silika yang lebih murni dan berstruktur amorf memiliki transisi gelas dan transisi fasa $\alpha \rightarrow \beta$-quartz yang lebih tinggi serta transisi fasa $\beta$-quartz $\rightarrow \beta$-tridymite yang lebih rendah dibandingkan sampel yang masih mengandung karbonat. Sinter silika yang dihasilkan dari mata air panas Sapan Maluluang dapat dimanfaatkan untuk aplikasi yang memerlukan transisi gelas yang lebih tinggi.

\section{UCAPAN TERIMA KASIH}

Penelitian ini didukung dan didanai oleh FMIPA Universitas Andalas dengan kontrak No. 06/UN.16.03.D/PP/FMIPA/2018. 


\section{DAFTAR PUSTAKA}

1. Dona, R.M. dan Putra, A., Jurnal Fisika Unand 5(3), 199-204 (2016).

2. Endhovani, R. dan Putra, A, Jurnal Fisika Unand 5(1), 65-72 (2016).

3. Gallagher, P.K., Handbook of Thermal Analysis and Calorimetry (Elsevier, Amsterdam, 1998)

4. Herdianita, N. R., Brown, P. R., Rodges, K. A., \& Cambell, K. A., Mineralium Doposita 35(1), 48-62 (2000).

5. Putra, A., Inanda, D. Y., Buspa, F., \& Salim, F. A., Journal of Physics: Conference Series 997, 1-5 (2017)“

6. Smallman, R. E., \& Bishop, R.J., Metalurgi Fisik Modern dan Rekayasa Material (Erlangga, Jakarta, 2000)

7. Valles, M.G., Turiel J.L., Torrente, D.G., Alonso, J.S., Manent, S.M., American Mineralogist 93 1373-1383 (2008) 